\title{
Acculturation, immigration status and cardiovascular risk factors among Portuguese immigrants to Luxembourg: findings from ORISCAV-LUX study
}

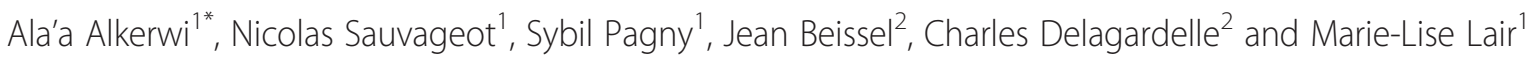

\begin{abstract}
Background: No previous study has examined the prevalence of cardiovascular risk factors and explored the influence of immigration status and acculturation on overweight/obesity among the Portuguese immigrants to Luxembourg. Our objectives were to (1) compare the prevalence of cardiovascular risk factors between native Luxembourgers and Portuguese immigrants, (2) examine the relationship between immigrant generation status, proportion of life spent in Luxembourg and language proficiency or preference (as proxy variables of acculturation) and overweight/obesity among Portuguese immigrants, and (3) elucidate the role of underlying socioeconomic, behavioral and dietary factors in overweight/obesity differences among the two populations.

Methods: Recent national cross-sectional data from ORISCAV-LUX survey 2007-2008, composed of 843 subjects were analyzed. Overweight/obesity was defined as body mass index (BMI) $>25 \mathrm{~kg} / \mathrm{m}^{2}$. Acculturation score was measured by using immigrant generation status, proportion of life spent in Luxembourg, and language proficiency or preference. Univariable and multivariable logistic regression analyses were performed to examine the association between acculturation markers and overweight/obesity. Further, a series of successive models were fitted to explore the separated and added impact of potential mediators (socioeconomic status, physical activity, dietary factors) on overweight/obesity among Luxembourgers and Portuguese immigrants.
\end{abstract}

Results: Compared to Luxembourgers, Portuguese immigrants of first and second generation were younger and currently employed. About $68 \%$ of first generation Portuguese had only primary school, and about $44 \%$ were living below poverty threshold. Although the cardiovascular risk factors were comparable, Portuguese immigrants were more frequently overweight and obese than Luxembourgers, even after age and gender standardization to the European population. Overweight/obesity was significantly higher among Portuguese of first generation compared to second generation $(P=0.028)$. Although we observed a tendency of lower risk with higher acculturation, none of the acculturation markers, both individually and taken together as a score, was statistically significant after controlling for age and gender. Compared to Luxembourgers, odds of overweight/obesity were significantly higher among Portuguese immigrants, in unadjusted model 1 ( $P=0.043$ ), in age and gender-adjusted model 2 ( $P<0.0001)$, in socioeconomic status adjusted model $3(P=0.01)$, in physical activity adjusted model $4(P=0.007)$. However, this difference was attenuated and statistically disappeared after controlling for dietary factors $(P=0.09)$.

(Continued on next page)

\footnotetext{
* Correspondence: alaa.alkerwi@crp-sante.lu

${ }^{1}$ Centre de Recherche Public de la Santé, Centre d'Etudes en Santé, 1A rue

Thomas Edison, Strassen L-1445, Grand-Duchy of Luxembourg

Full list of author information is available at the end of the article
} 
(Continued from previous page)

Conclusions: These findings address a lack of heterogeneity between Portuguese immigrants and Luxembourgers regarding hypertension, hyperlipidemia, diabetes mellitus, physical inactivity, and current cigarette smoking. However, Portuguese immigrants to Luxembourg were more likely to be overweight/obese than Luxembourgers participants. This risk may be explained by different dietary practice. An in-depth comparative assessment of dietary habits of Luxembourgers and Portuguese immigrants is warranted.

Keywords: Cardiovascular risk factors, Acculturation, Portuguese immigrants, Cross-sectional study

\section{Background}

Cardiovascular diseases are the leading cause of mortality in Europe, accounting for more than $48 \%$ of all European deaths, with striking geographical variations [1]. Cigarette smoking, obesity, lipid disorders, elevated blood pressure and diabetes mellitus are not only associated with each other but also with high cardiovascular morbidity and mortality $[2,3]$.

The Grand-Duchy of Luxembourg is a small country in the heart of Europe landlocked by Belgium, France and Germany, with a population of 511840 inhabitants (official estimate, 2011) over an area of about $2600 \mathrm{~km}^{2}$. Cardiovascular mortality accounted for nearly one-third of death in 2010 [4]. According to a recent nationwide cross-sectional survey, the most predominant cardiovascular risk factors were dyslipidemia (69.9\%), hypertension (34.5\%), smoking (22.3\%), obesity (20.9\%), and diabetes $4.4 \%$ [5].

Distinctively, Luxembourg country is a multicultural society; about $43.2 \%$ of the people are foreign residents from over 150 different nationalities, among those, the Portuguese representing the major immigrant community (36.7\%). According to the National Institute of Statistics (2011), Portuguese immigrants constitute $15.9 \%$ of the total Luxembourg population with a steady increase during the last decades [6]. Presently, about 80,000 people with Portuguese nationality reside in Luxembourg, following successive waves of post-war migration, associated with labor shortage. Evidently, the national health profile is significantly determined by the health of its immigrants.

Primary care physicians of Luxembourg have observed during the last decades that Portuguese immigrants to Luxembourg are more susceptible to develop cardiovascular diseases and are at higher risk of obesity, hypertension, lipid disorders and diabetes, compared to native Luxembourgers. However, this phenomenon observed by physicians needs to be supported by concrete evidencebased data. Several studies carried out in different countries worldwide, but mostly in American settings $[7,8]$, suggest an influence of migration on the prevalence of cardiovascular risk factors. Cultural factors have been linked to poor health practices and risk of diabetes [9], hypertension [10], and obesity [11,12]. On the other hand, the literature suggests that migration may also have positive protective effects on obesity risk among lower income black immigrants to U.S. [13]. Diet quality of Tunisian migrants to the south of France partly explained their lower prevalence of diet-related chronic conditions compared to their native French peers [14]. On whole, health effects of acculturation vary by country of origin, health behaviors and outcome being studied; immigration and subsequent behavior changes may contribute either to the development or the decline of several cardiovascular disorders, such as obesity and diabetes [11,15].

Although Portuguese immigrants represent a large and growing segment of the Luxembourg population, it is unknown how cardiovascular risk factors differ between Portuguese immigrants and Luxembourgers. The particularity of Portuguese community constitutes an excellent opportunity to explore the implication of immigration on cardiovascular health in Luxembourg. The objectives of this study were to (1) compare the prevalence of cardiovascular risk factors between native Luxembourgers and Portuguese immigrants, (2) examine the relationship between immigrant generation status, proportion of life spent in Luxembourg and language proficiency or preference (as proxy variables of acculturation) and overweight/ obesity among Portuguese immigrants, and (3) elucidate the role of underlying socioeconomic, behavioral and dietary factors in overweight/obesity differences among the two populations.

For these purposes, we used recent national crosssectional data from ORISCAV-LUX survey (Observation of cardiovascular risk factors in Luxembourg, 2007-2008) [5]. Understanding the consequences of acculturation for obesity and its associated risk factors will have important implications which help to improve cardiovascular prevention for the whole population of Luxembourg.

\section{Methods}

\section{Data sources}

ORISCAV-LUX survey is the first nationwide populationbased study carried out on a weighted random sample stratified according to age, sex and district (Luxembourg, Diekirch and Grevenmacher), of non-institutionalized adults, aged 18-69 years, residing in Luxembourg. The distribution of selected subjects in each stratum was 
proportional to their distribution in the source population. Further details concerning the aims, data collection, and sample representativeness have been reported elsewhere $[5,16]$. Briefly, information on demographic, socioeconomic and health-related characteristics was collected, with the help of trained personnel, via a self-administered questionnaire in French, German, Portuguese and English. The questionnaire was forward and backward-translated to French by independent certified translators and reviewed by multilingual staff. A total of 1432 subjects were recruited, of whom 191 were Portuguese immigrants and 652 Luxembourgers. Given the research objectives, only Portuguese participants were included in the analyses along with native Luxembourgers. The analyses were thus based on a sample of 843 subjects, excluding subjects with missing data on place of birth or length of residence in Luxembourg, and those from other different origins.

\section{Cardiovascular risk factors}

Six cardiovascular risk factors of interest were studied: obesity/overweight, hypertension, hyperlipidemia, diabetes mellitus, physical inactivity, and current cigarette smoking, which were measured according to standard protocol procedures, as reported earlier [5].

Subjects with body mass index (BMI) $>25 \mathrm{~kg} / \mathrm{m}^{2}$ were considered as overweight/obese [17]. BMI was calculated by dividing weight $(\mathrm{kg})$ by the square of height $(\mathrm{m})$, and coded as a dichotomous variable (obesity/overweight vs normal weight).

Data on diabetes, hyperlipidemia, and hypertension were all based on biological and objective measurements, as reported elsewhere [5,18]. Precisely, participants were classified as having elevated blood pressure if they reported taking anti-hypertensive medications and/or had SBP $\geq 140 \mathrm{mmHg}$ and/or DBP $\geq 90 \mathrm{mmHg}$ [19]. Participants were classified as diabetics if they reported taking anti-diabetic medications and/or had FPG $\geq 126 \mathrm{mg} / \mathrm{dl}$ [20]. Subjects with lipid disorder were defined as having at least one of the following anomalies: TC $\geq 190 \mathrm{mg} / \mathrm{dl}, \mathrm{TG} \geq 150 \mathrm{mg} / \mathrm{dl}, \mathrm{LDL}-\mathrm{C} \geq 115 \mathrm{mg} /$ $\mathrm{dl}$, and HDL-C $<40 \mathrm{mg} / \mathrm{dl}$ for men and $<46 \mathrm{mg} / \mathrm{dl}$ for women [21], and/or taking hypo-lipid medications. These were coded as dichotomous variables (yes vs no) based on presence or absence of the relevant disease condition.

Smoking status was categorized as current smoker or non-smoker (which included former smokers and never smokers). Physical activity was self-reported using the International Physical Activity Questionnaire IPAQ [22], which categorizes the population into three levels: physically inactive, moderately active and active. The last 2 categories were regrouped into (active) versus (inactive).

\section{Acculturation variables}

To examine the effect of acculturation on obesity differences between Portuguese immigrants, four measures were used: immigrant generation status, language proficiency or preference, proportion of life spent in Luxembourg, and acculturation score.

\section{Immigrant generation status}

The studied population was divided into 2 groups according to immigration status (Portuguese immigrants and native Luxembourgers). Portuguese immigrants were referred to both first and second generation of Portuguese immigrants to Luxembourg; participants who were born in Portugal were classified as "first generation"; participants who were born in Luxembourg and had one or both parents born in Portugal were classified as "second generation". Generation is an important proxy measure that can provide important insight into the historical and geographical context, in addition to baseline cultural characteristics of the individual $[23,24]$. Those who were born in Luxembourg as were both parents were considered as native born "Luxembourgers". A score of 1-3 was assigned to immigration status ( $1=$ Portuguese first generation, $2=$ Portuguese second generation, $3=$ Luxembourgers)

\section{Language proficiency or preference}

Language proficiency or preference during interview is a strong predictor of acculturation [25]. The participant indicated his/her preferred language to answer the selfadministered questionnaire. The selection of either French or German, the two official languages in Luxembourg, represents dominance and proficiency with that language. A score of $0-1$ was assigned to language proficiency or preference ( $0=$ Portuguese, $1=$ French or German).

\section{Proportion of life spent in Luxembourg}

Length of residency is an interesting indicator of exposure to the culture of the host country. As suggested by assimilation theory [26], the course of time and the exposure to the new culture can influence host satisfaction, which posits that immigrants will progressively converge into the mainstream. The number of years of residency in Luxembourg divided by age provides a fraction that indicates the proportion of an individual's life spent in the second culture [27]. This continuous variable is ranged from 0.04 to maximum 1 (for those of second generation). Precisely, the minimum value means a subject of 55 years age who have been in Luxembourg since 2 years, then $(2 / 55=0.0366)$. The maximum value of the score indicates that a Portuguese subject spent all his life in Luxembourg (i.e., born in Luxembourg, so the period of residency $=$ the age $=1$ ). 


\section{Acculturation score}

Similar to other research studies, a single summary acculturation score for each participant has been constructed, by summing the three individual indicators (immigrant generation status + language proficiency/preference + proportion of life spent in Luxembourg). It ranged from 1 (least acculturated) to 5 (most acculturated). The acculturation score has advantage that it takes into account simultaneously the characteristics which are often clustered within an individual. The combination of markers may give a more accurate representation of acculturation than each indicator independently [11].

\section{Other variables}

Socio-demographic variables included age, gender, socioeconomic status (SES) as measured by level of education and income.

Concerning dietary habits, percentage of total daily energy intake of fat (\%E), percentage of total daily energy intake of carbohydrates (\%E), percentage of total daily energy intake of protein (\%E) and fibers (grams per day) were estimated from the semi-quantitative self-administered Food Frequency questionnaire (FFQ) [28]. Full details concerning the calculation of variables have been published elsewhere [29].

\section{Ethical aspects}

The present study was conducted according to the guidelines laid down in the Declaration of Helsinki and all procedures involving human subjects were approved by the National Research Ethics Committee (Comité National d'Ethique de Recherche, CNER) and the National Commission for Private Data Protection (Commission Nationale pour la Protection des Données, CNPD). Written informed consent was obtained from all the subjects.

\section{Statistical analysis}

Initially, participants' characteristics by immigration status (in three categories) were compared and the P-values were presented. Each two groups were again compared and the difference was indicated whenever significant, by using the test of Kruskal-Wallis for non-normally distributed variables, an ANOVA for normally distributed variables, and $X^{2}$ test for categorical variables.

Then, the six cardiovascular risk factors of interest (overweight/obesity, hypertension, dyslipidemia, diabetes mellitus, current cigarette smoking, and physical inactivity) were compared between the Luxembourgers and Portuguese immigrants. To facilitate a meaningful comparison between these two populations, with different age and gender composition, direct standardization method was applied to remove the effects of variation in age and gender structure using the European population as reference.
Further, univariable and multivariable logistic regression models were fitted to investigate the effect of acculturation, measured by three proxy indicators (immigrant generation status, length of residency/age and language proficiency or preference) on overweight/obesity among Portuguese immigrants. The effect of acculturation was tested by using each indicator individually and then by using the score which is the sum of the three proxy indicators. Portuguese of second generation and French/German were used as referents for immigrant generation status and language proficiency, respectively. A graphic presentation of the odds ratio and $95 \%$ confidence intervals are displayed in a Forest plot.

To explore the separated and added impact of potential mediators (SES, physical activity, dietary factors) on overweight/obesity among Luxembourgers and Portuguese immigrants, a series of successive models were fitted by adding, to the crude unadjusted Model 1, age and gender in Model 2; socioeconomic variables in Model 3; the physical activity in Model 4 and dietary factors in Model 5. Precisely, model 1=unadjusted; Model 2=adjusted for age and gender; Model 3=Model 2 plus SES (education in three categories; income in two categories); Model $4=$ Model 3 plus physical activity in three categories); Model $5=$ Model 4 plus dietary factors (total fat in percent Kilocalories, total carbohydrate in percent Kilocalories, total protein in percent Kilocalories, and total fiber in gram).

Results were considered significant at the $5 \%$ critical level $(\mathrm{P}<0.05)$. All statistical analyses were performed using $\mathrm{PASW}^{\oplus}$ for $\mathrm{Windows}^{\oplus}$ version 18.0 software (formerly SPSS Statistics Inc.)

\section{Results}

\section{Characteristics of studied population according to} immigration status

The characteristics of Luxembourgers and Portuguese Immigrants of first and second generation are presented in Table 1. Compared to Luxembourgers, Portuguese immigrants of first and second generation were significantly younger $(P<0.0001)$ and currently employed. However, the educational attainment and income of first generation Portuguese were much lower than that of Luxembourgers and their counterpart of second generation. About $68 \%$ of first generation Portuguese had only primary school, and about $44 \%$ were living below poverty threshold. A remarkable economic status gradient between the two generations was also observed, in favor of the second generation immigrants.

Luxembourgers reported considerably higher percentages of energy from fat than the Portuguese immigrants of first and second generation $(P<0.0001)$, but with lower percentages of energy from carbohydrates intake $(P=0.009)$. 
Table 1 Characteristics of studied population according to immigration status, ORISCAV-LUX survey, 2007-2008

\begin{tabular}{|c|c|c|c|c|}
\hline & $\begin{array}{c}\text { Portuguese } 1^{\text {st }} \text { generation } \\
\%(\mathrm{~N})\end{array}$ & $\begin{array}{c}\text { Portuguese } 2^{\text {nd }} \text { generation } \\
\%(\mathrm{~N})\end{array}$ & $\begin{array}{c}\text { Luxembourgers } \\
\%(\mathrm{~N})\end{array}$ & $P$ valuet \\
\hline$n$ & 169 & 22 & 652 & \\
\hline Age (years) $(n$ 843) * & $40.54 \pm 17$ & $30.6 \pm 7$ & $47.71 \pm 21$ & $<0.0001^{a, b, c}$ \\
\hline Gender & & & & 0.092 \\
\hline Men ( $n$ 410) & $55(93)$ & $59.1(13)$ & $46.6(304)$ & \\
\hline Women ( $n$ 433) & $45(76)$ & $40.9(9)$ & $53.4(348)$ & \\
\hline Education level (\%) & & & & $<0.0001^{\mathrm{a}, \mathrm{b}}$ \\
\hline Primary (n 245) & $67.7(113)$ & $13.6(3)$ & $20(129)$ & \\
\hline Secondary (n 418) & $28.7(48)$ & $54.5(12)$ & $55.6(358)$ & \\
\hline Tertiary (n 170) & $3.6(6)$ & $31.8(7)$ & $24.4(157)$ & \\
\hline Economic status (\%) & & & & $<0.0001^{\mathrm{a}, \mathrm{b}}$ \\
\hline below poverty threshold ( $n$ 144) & $44.4(68)$ & $16.7(3)$ & $13.2(73)$ & \\
\hline above poverty threshold ( $n$ 578) & $55.6(85)$ & $83.3(15)$ & $86.8(478)$ & \\
\hline Work status & & & & $<0.0001^{a, b, c}$ \\
\hline Employed ( $n$ 524) & $74.6(126)$ & $81.8(18)$ & $58.4(380)$ & \\
\hline Non-employed (n 76) & $7.1(12)$ & $18.2(4)$ & $9.2(60)$ & \\
\hline Housewife (n 107) & $8.3(14)$ & $0(0)$ & $14.3(93)$ & \\
\hline Retired (n 135) & $10.1(17)$ & $0(0)$ & $18.1(118)$ & \\
\hline Total dietary calories (Kcal) (n 796)* & $2121.63 \pm 1006$ & $2307.06 \pm 1353$ & $2274.18 \pm 1153$ & $0.032^{b}$ \\
\hline Fat (\% Kcal) (n 791) & $35.43 \pm 6.88$ & $37.54 \pm 4.93$ & $39.13 \pm 7.05$ & $<0.0001^{b}$ \\
\hline Carbohydrates (\% Kcal) (n 791) & $43.84 \pm 7.45$ & $44.22 \pm 6.21$ & $41.95 \pm 7.44$ & $0.009^{b}$ \\
\hline Fibers (g/day) $(n$ 796) * & $22.3 \pm 12$ & $20 \pm 18$ & $23.5 \pm 13$ & 0.207 \\
\hline
\end{tabular}

Data are expressed as means \pm SD, otherwise median (Inter-quartile interval) is indicated as*.

$P$ values are from $X^{2}$ tests for categorical variables, whereas ANOVA and Kruskal-Wallis were used for normally and non-normally distributed continuous variables, respectively.

† P-value indicates the comparison between the 3 groups.

a indicates that the P-value is significant when comparing Portuguese $1^{\text {st }}$ generation to Portuguese $2^{\text {nd }}$ generation

$\mathrm{b}$ indicates that the P-value is significant when comparing Portuguese $1^{\text {st }}$ generation to Luxembourgers.

$\mathrm{C}$ indicates that the $\mathrm{P}$-value is significant when comparing Portuguese $2^{\text {nd }}$ generation to Luxembourgers.

\section{Prevalence of cardiovascular risk factors between} Luxembourgers and Portuguese immigrants

After age and gender standardization to European population, the distribution of cardiovascular risk factors was almost similar in both populations, with no significant difference as regards hypertension, lipid disorders, diabetes, smoking status and physical inactivity, except for overweight/obesity which was more common in Portuguese immigrants than Luxembourgers (65.33\% vs $56.15 \%$, respectively, $P=0.012$ ). The observed increase in the age- and gender-standardized prevalence of hypertension ( $44.6 \%$ vs $38.2 \%$ ), dyslipidemia $(72.8 \%$ vs $71.4 \%)$ and diabetes ( $4 \%$ vs $3 \%)$ among Portuguese immigrants was not statistically significant (Figure 1).

In light of these findings, we focused on examining relationships between the overweight/obesity status and the acculturation among Portuguese of first and second generation, by using our proxy variables of acculturation.
Portuguese was the preferred language for $70 \%$ of first generation Portuguese immigrants, whereas French or German were preferred for $80 \%$ of second generation. As expected, mean acculturation score was substantially higher in second than the first generation $(3.86 \pm 0.35 \mathrm{vs}$ $1.75 \pm 0.59$, respectively). The overweight/obesity was significantly higher in first compared to second generation of Portuguese immigrants $(P=0.028)$ (Table 2).

\section{Effect of generation, proportion of life spent in} Luxembourg and language proficiency on overweight/ obesity among Portuguese immigrants to Luxembourg On examination of Portuguese immigrants' population, first generation participants were at about two-fold odds to be overweighed/obese compared to second generation participants. This overweight/obesity-generation status association was only significant in the crude (unadjusted) model (OR=2.68; 95\%CI: 1.09-6.56). In age and sex-adjusted model, the gradient of risk of overweight/obesity disappeared for the first compared to the 


\section{$P=0.52$}

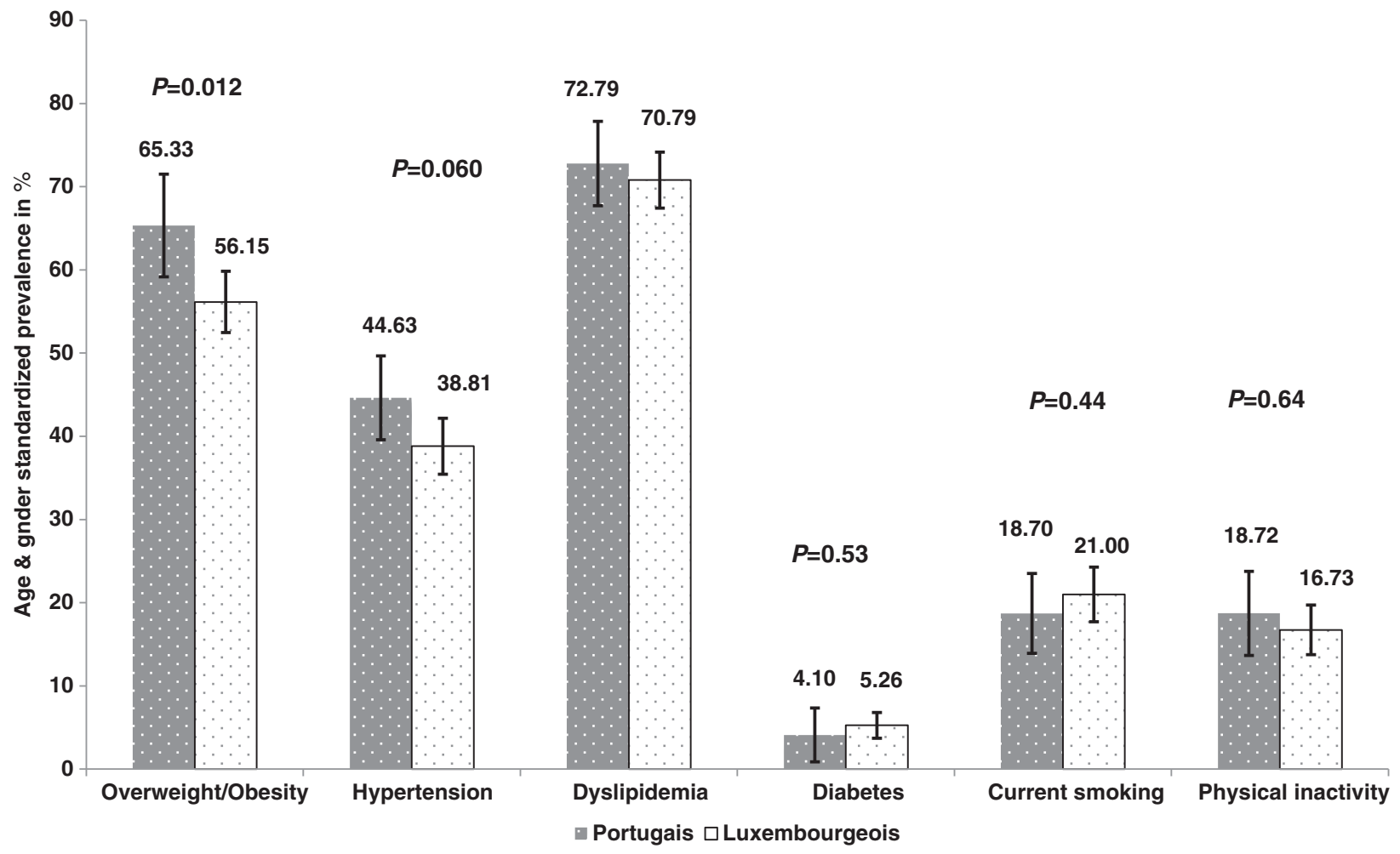

Figure 1 Comparison between Luxembourgers and Portuguese participants according to selected cardiovascular risk factors, ORISCAV-LUX survey, 2007-2008.

second generation Portuguese immigrants $(\mathrm{OR}=1.73$; 95\%CI: 0.65-4.60). Likewise, the odds ratios for those who prefer Portuguese were higher in both crude $(\mathrm{OR}=$ 1.56; 95\% CI: 0.84-2.88) and adjusted models (OR=1.12; 95\% CI: 0.56-2.22) than those who prefer French/ German, although this was not statistically significant. Regarding the proportion of life spent in Luxembourg, measured by the length of residency/age, higher fraction showed lower odds ratios in both crude $(\mathrm{OR}=0.46 ; 95 \%$ IC: $0.15-1.37)$ and adjusted model $(\mathrm{OR}=0.60 ; 95 \%$
IC: 0.19- 1.90), but without sensible statistical significance. With regard to acculturation score, the magnitude and the significance of effect on overweight/ obesity prevalence was slightly protective in the crude model, but this effect disappeared in the adjusted model (Figure 2).

In the next step, we focused on the role of underlying socioeconomic, behavioral and dietary factors in overweight/obesity differences among the two populations (Portuguese immigrants and Luxembourgers).

Table 2 Description of overweight/obesity and acculturation markers among Portuguese immigrants

\begin{tabular}{|c|c|c|c|}
\hline & $\begin{array}{l}\text { Portuguese } 1^{\text {st }} \text { generation } \\
(n=196)\end{array}$ & $\begin{array}{l}\text { Portuguese } 2^{\text {nd }} \text { generation } \\
(n=22)\end{array}$ & $P$-value* \\
\hline Language proficiency \% (n) & & & $<0.0001$ \\
\hline Portuguese (n 121) & $69.8(118)$ & $13.6(3)$ & \\
\hline French/German ( $n$ 70) & $30.2(51)$ & $86.4(19)$ & \\
\hline Length of residency/age (means \pm SD) & $0.45 \pm 0.23$ & 1 & \\
\hline Acculturation score (means \pm SD) & $1.75 \pm 0.59$ & $3.86 \pm 0.35$ & \\
\hline Overweight/obesity \% (n) & $69(116)$ & $45.5(10)$ & 0.028 \\
\hline
\end{tabular}

* P-value from $X 2$ tests for categorical variables. 


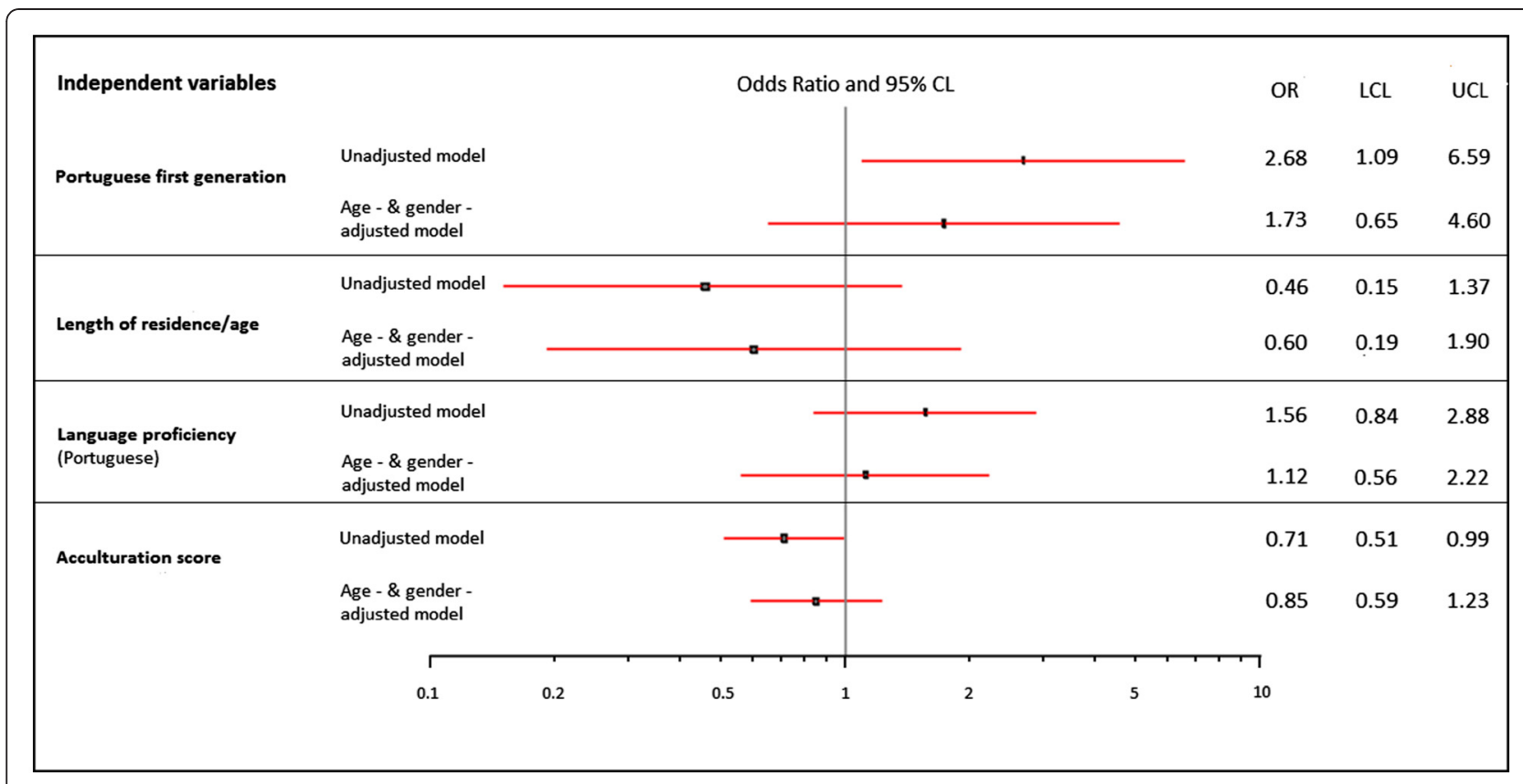

Figure 2 Odds ratio and $95 \%$ confidence intervals for the association of overweight/obesity and acculturation among Portuguese immigrants, measured individually and by score, ORISCAV-LUX survey, 2007-2008.

Role of underlying socioeconomic, behavioral and dietary factors in overweight/obesity differences between Luxembourgers and Portuguese immigrants

Given that only overweight/obesity was significantly higher in Portuguese immigrants compared to Luxembourgers, we ran a series of models to examine the extent to which SES, physical activity and dietary factors explain this disparity. We found that odds of being overweight/obese were significantly higher among Portuguese immigrants as compared to Luxembourgers, in unadjusted model $1(P=0.043)$, and in age and genderadjusted model $2(P<0.0001)$. The difference was still significant, by adding socioeconomic status $(P=0.01$ in model 3$)$, physical activity ( $P=0.007$ in model 4$)$, in the sense that Portuguese immigrants were at about doublefold odds to be overweight/obese compared to Luxembourgers. However, this difference was attenuated and statistically disappeared after controlling for dietary factors $(P=0.09)$ (Table 3$)$.

\section{Discussion}

In line with traditional countries of immigration, such as Australia, Canada and the United States, the issue of migrant health receives increasing attention in Europe [30], and particularly in Luxembourg. Accurate data on the health of Portuguese migrants are an essential precondition for providing appropriate and accessible health services to this population group.
In contrast to the widespread opinion among the general practitioners, this analysis of a large national sample documented, for the first time, an absence of heterogeneity between Luxembourgers and Portuguese immigrants to Luxembourg, concerning the most important preventable and potentially modifiable cardiovascular risk factors, except the higher overweight/obesity among the Portuguese. As in most European countries, the organization of Luxembourg's health care services ensures equal access and utilization to different immigrant groups. In addition, a number of measures were already implemented by policy-makers to improve access of immigrants to health services. These include overcoming language barriers and poor communication by providing interpretation and regular Portuguese translation of official documents. The translated documents help publicizing health education messages to immigrants. Therefore, our findings may reflect a national parity in health and equal opportunities to care access.

Prior studies have suggested mixed evidence concerning the relationship between acculturation, lifestyle behaviors, and cardiovascular risk factors among immigrants $[7,8]$. Several studies suggest that acculturation is associated with some positive healthy behaviors, such as leisure-time physical activity [31], whereas others suggest that the positive health behaviors decline with acculturation [32,33]. It is noteworthy that similar prior studies were largely carried 
Table 3 Simple and adjusted logistic regression models of prevalent overweight/obesity among Luxembourgers and Portuguese immigrants, ORISCAV-LUX survey, 2007-2008

\begin{tabular}{|c|c|c|c|}
\hline & \multicolumn{2}{|c|}{ Odds ratio $(95 \% \mathrm{Cl})$} & \multirow[t]{2}{*}{$P$ value } \\
\hline & $\begin{array}{l}\text { Luxembourgers } \\
\qquad(n \text { 652) }\end{array}$ & $\begin{array}{l}\text { Portuguese immigrants } \\
\text { (n 191) }\end{array}$ & \\
\hline Model 1 unadjusted & Referent & $1.42(1.01-1.99)$ & 0.043 \\
\hline Model 2 adjusted for age and sex & Referent & $2.08(1.42-3.03)$ & $<0.0001$ \\
\hline Model 3 (Model 2+ SES) & Referent & $1.83(1.16-2.90)$ & 0.01 \\
\hline Model 4 (Model 3+ physical activity) & Referent & $1.91(1.19-3.08)$ & 0.007 \\
\hline Model 5 (Model 4 + dietary factors) & Referent & $1.57(0.93-2.65)$ & 0.09 \\
\hline
\end{tabular}

out in US, few studies carried out in Europe, and even none in Luxemburg.

Luxembourg's immigration rate rose sharply in the course of the last century, with a noticeably important influx of Portuguese immigrants during the last 40 years. In contrast to the tendency of other minorities, a large majority of Portuguese immigrants seem to keep their original culture. The geographical proximity to their country of origin allows for frequent contact and travel. Many resident Portuguese continue to speak Portuguese and are closely tied to their cultural roots; however, many do learn the official languages of Luxembourg (French and German, beside Luxembourgish), integrate the new culture, and thus become bicultural and multilingual to different extents. The distinct cultural particularity of Portuguese immigrants to Luxembourg provided the opportunity to examine the overweight/ obesity-acculturation relationship among Portuguese of first and second generation. For this objective, we considered three proxy indicators including proportion of life spent in Luxembourg, language proficiency or preference, and immigrant generation status. Although none of the acculturation markers, both individually and taken together as a score of acculturation, were statistically significant after controlling for age and gender, we observe a tendency of lower risk with higher acculturation. The absence of statistically sensible effect may be related to low sample size of Portuguese of second generation. In fact, the selected ORISCAV-LUX sample was representative of the source population with respect to nationality, however, the participation rate was lower in Portuguese residents $(13.62 \%, n$ 195) as compared to Luxembourgers (62.08\%, $n$ 889) [16]. Positively, the breadths of confidence intervals were not excessively wide-ranging, particularly for the acculturation score, which gives a more accurate representation of acculturation than each indicator alone. These confidence intervals provide an 'estimate interval', which gives us a measure of 'precision' or 'confidence' around our point estimate; wide confidence intervals indicate lack of precision [34]. Therefore, we globally concluded that the most acculturated Portuguese immigrants seemed to be protected and less susceptible to be overweighed/obese than the least acculturated. The absence of levelheaded association is probably because the effect size (culture) is too small to get a statistically significant result, i.e., although may exist, it couldn't be detected by the actual sample size.

Another potential explanation of our finding may be related to the "healthy migrant effect phenomenon" [35]. Although immigrants face particular health challenges and are vulnerable to a number of threats to their physical and mental health, they are often healthy and enjoy a good health to work, notably in case of successive labor Portuguese migration.

In addition, the prevalence of main cardiovascular risk factors, in particular overweight/obesity are highly elevated both in Portugal [36] and in Luxembourg [5]. This homogeneity between the two populations may limit the ability to detect a discriminative effect of acculturation.

Overweight/obesity is a national public health problem. According to previous ORISCAV-LUX survey findings, more than $50 \%$ of adults' residents in Luxembourg were affected, the prevalence increased with age, and varied by country of birth [5]. In this study, we documented a higher prevalence of overweight/obesity among Portuguese immigrants compared to Luxembourgish participants. About two-fold odds associated with migration status (Luxembourgers versus Portuguese immigrants) remained after adjustment for age, gender, and socioeconomic status. Further adjustment for physical activity did not significantly change this association, but adjustment for dietary factors attenuated the relationship between migration status and overweight/obesity. This finding suggests that diet may be an important contributor to the risk of overweight/obesity in Portuguese immigrants and dietary practice may explain the high likelihood of overweight/ obesity among Portuguese subjects. 
Owing to the total lack of knowledge concerning the health status of Portuguese immigrants to Luxembourg, the current study constitutes the first exploratory study to address the prevalence of cardiovascular risk factors between Luxembourgers and Portuguese immigrants and thus fill in the gap knowledge as regards cardiovascular health and immigration status in Luxembourg. It confers a valuable baseline evidence for health professionals, hospital managers and public health decision-makers to obtain more knowledge on Portuguese migrants' health.

Despite the unique and innovative findings which are based on recent data (2007-2008), the study has however several limitations. It is possible that only healthier Portuguese have participated and hence little variability was detected between Portuguese and Luxembourgers, as regards the cardiovascular risk factors. Despite the observed protective tendency of acculturation, the small sample size of second generation might limit the statistical power to detect a sensible meaningful association between acculturation and overweight/obesity. However, low response rates and small sample sizes are typical limitations in most immigrant data collected from the population-based surveys, which may partly explain the important heterogeneity in the literature regarding the association between acculturation, health behaviors and chronic disease prevalence [9].

The ORISCAV-LUX survey was primarily not designed to examine migration and acculturation effect among minorities. However, it provided information on four proxy measures of acculturation [33]: language proficiency or preference, length of residency/age (proportion of life lived in Luxembourg), immigrant's generation and country of birth. The majority of studies on health and acculturation use different measures of acculturation, and this variation may account for different results across the studies. Although the proxy measures have been widely used in similar studies $[23,24,27]$, these variables do not fully capture the complex process of acculturation and its health effects [11]. Acculturation is an indication of the cultural change of minority individuals to the majority culture. Across literature, the relationship between acculturation and health status in immigrant population vary widely according to the construct used, immigrant population, and outcomes of interest. It has been demonstrated that when thoroughful assessments of acculturation are unfeasible or unavailable, shorter proxy measures can be useful and constitute suitable substitutes to assess acculturation, with several advantages: simplicity of assessment, feasibility of collection in large health surveys, and limited respondent burden [37].

Given the high prevalence of cardiovascular risk factors among our growing multicultural society in Luxembourg, a future larger scale cross-cultural study is warranted.

\section{Conclusions}

In conclusion, the cross-sectional analysis, adjusted for age, gender, socioeconomic status and physical activity, revealed that Portuguese immigrants to Luxembourg were generally more likely to be overweight/obese than native Luxembourger participants. This risk may be explained by the dietary factors. From public health standpoint, these findings are important in delineating the groups at risk of overweight, given the substantial increase in overweight and obesity-associated morbidity and mortality.

\section{Perspectives}

In order to design appropriate public health policies and health promotion interventions, greater consideration of the cultural environment may be warranted [38]. In this regard, an in-depth cross-cultural analysis of dietary habits between Luxembourger and Portuguese participants will increase our understanding of the potential influence of cultural environments on diet composition [39].

Another challenging avenue of future research is to compare the cardiovascular risk of Portuguese immigrants to that of those living in Portugal. Such crossnation comparison is relevant for etiological purposes, and allows demonstrating and quantifying the contribution of different types of factors, including genetic factors, early living conditions, behavioral factors, health and integration policies, and their interactions on health status of immigrants.

\section{Competing interests}

The authors declare that they have no competing interests.

\section{Authors' contributions}

AA was involved in the conception and design of the ORISCAV-LUX survey, coordinated the field data collection, conceived the present research, contributed to data analyses and drafted the manuscript. NS and SP performed the statistical analyses and discussion of the results. JB, CDG Cardiologists contributed to the critical revision of the manuscript. M-LL was involved in the instigation of the ORISCAV-LUX study and critical revision of the manuscript. All authors reviewed and approved the final version of the manuscript.

\section{Acknowledgements}

The present study was supported by a research grant from the National Fund of Research (Fond National de Recherche; project MSF, 784844, BM). We are grateful to Professor Stephan Senn for his valuable comments on manuscript preparation and revision.

\section{Author details}

'Centre de Recherche Public de la Santé, Centre d'Etudes en Santé, 1A rue Thomas Edison, Strassen L-1445, Grand-Duchy of Luxembourg. ${ }^{2}$ Centre

Hospitalier de Luxembourg, 4, rue Barblé, Luxembourg L-1210, Grand-Duchy of Luxembourg.

Received: 25 May 2012 Accepted: 5 October 2012

Published: 11 October 2012 


\section{References}

1. Allender S, Scarborough P, Peto V, Rayner M: European cardiovascular disease statistics, British Heart Foundation Health Promotion Research Group; 2008:1-112.

2. Kannel WB: Update on the role of cigarette smoking in coronary artery disease. Am Heart J 1981, 101(3):319-328.

3. Vartiainen E, Sarti C, Tuomilehto J, Kuulasmaa K: Do changes in cardiovascular risk factors explain changes in mortality from stroke in Finland? BMJ 1995, 310(6984):901-904.

4. Ministry of Health: National Statistics of all causes of death, Luxembourg Statistiques des causes de décès pour l'année; 2010. Accessed on http://www. sante.public.lu/fr/maladies-traitements/070-statistiques-causes-deces/index.html.

5. Alkerwi A, Sauvageot N, Donneau AF, Lair ML, Couffignal S, Beissel J, Delagardelle C, Wagener Y, Albert A, Guillaume M: First nationwide survey on cardiovascular risk factors in Grand-Duchy of Luxembourg (ORISCAVLUX). BMC Publ Health 2010, 10:468.

6. STATEC NSI: Luxembourg in Figures; 2011. http://wwwstatecpubliclu/en/ publications/indexhtml.

7. Sundquist J, Winkleby MA: Cardiovascular risk factors in Mexican American adults: a transcultural analysis of NHANES III, 1988-1994. Am J Public Health 1999, 89(5):723-730.

8. Koya DL, Egede LE: Association between length of residence and cardiovascular disease risk factors among an ethnically diverse group of United States immigrants. J Gen Intern Med 2007, 22(6):841-846.

9. Jaber LA, Brown MB, Hammad A, Zhu Q, Herman WH: Lack of acculturation is a risk factor for diabetes in arab immigrants in the US. Diabetes Care 2003, 26(7):2010-2014.

10. Kaplan MS, Chang C, Newsom JT, MCFarland BH: Acculturation status and hypertension among Asian immigrants in Canada. J Epidemiol Community Health 2002, 56(6):455-456.

11. Kandula NR, Diez-Roux AV, Chan C, Daviglus ML, Jackson SA, Ni H, Schreiner PJ: Association of acculturation levels and prevalence of diabetes in the multi-ethnic study of atherosclerosis (MESA). Diabetes Care 2008, 31(8):1621-1628

12. Gordon-Larsen P, Harris KM, Ward DS, Popkin BM: Acculturation and overweight-related behaviors among Hispanic immigrants to the US: the National Longitudinal Study of Adolescent Health. Soc Sci Med 2003, 57(11):2023-2034.

13. Bennett GG, Wolin KY, Askew S, Fletcher R, Emmons KM: Immigration and obesity among lower income blacks. Obesity (Silver Spring) 2007, 15(6):1391-1394

14. Mejean C, Traissac P, Eymard-Duvernay S, El Ati J, Delpeuch F, Maire B: Influence of socio-economic and lifestyle factors on overweight and nutrition-related diseases among Tunisian migrants versus non-migrant Tunisians and French. BMC Publ Health 2007, 7:265.

15. Pan YL, Dixon Z, Himburg S, Huffman F: Asian students change their eating patterns after living in the United States. J Am Diet Assoc 1999, 99(1):54-57.

16. Alkerwi A, Sauvageot N, Couffignal S, Albert A, Lair ML, Guillaume M: Comparison of participants and non-participants to the ORISCAV-LUX population-based study on cardiovascular risk factors in Luxembourg. BMC Med Res Methodol 2010, 10:80.

17. Clinical guidelines on the identification, evaluation, and treatment of overweight and obesity in adults: executive summary. Expert Panel on the Identification, Evaluation, and Treatment of Overweight in Adults. Am J Clin Nutr 1998, 68(4):899-917.

18. Alkerwi A, Donneau AF, Sauvageot N, Lair ML, Scheen A, Albert A, Guillaume M: Prevalence of the metabolic syndrome in Luxembourg according to the Joint Interim Statement definition estimated from the ORISCAV-LUX study. BMC Publ Health 2011, 11(1):4.

19. Mancia G, De Backer G, Dominiczak A, Cifkova R, Fagard R, Germano G, Grassi G, Heagerty AM, Kjeldsen SE, Laurent S, et al: 2007 Guidelines for the Management of Arterial Hypertension: The Task Force for the Management of Arterial Hypertension of the European Society of Hypertension (ESH) and of the European Society of Cardiology (ESC). $J$ Hypertens 2007, 25(6):1105-1187.

20. Ryden L, Standl E, Bartnik M, Van den Berghe G, Betteridge J, de Boer MJ, Cosentino F, Jonsson B, Laakso M, Malmberg K, et al: Guidelines on diabetes, pre-diabetes, and cardiovascular diseases. Rev Esp Cardiol 2007, 60(5):1e-64e.
21. De Backer G, Ambrosioni E, Borch-Johnsen K, Brotons C, Cifkova R, Dallongeville J, Ebrahim S, Faergeman O, Graham I, Mancia G, et al: European guidelines on cardiovascular disease prevention in clinical practice. Third Joint Task Force of European and Other Societies on Cardiovascular Disease Prevention in Clinical Practice. Eur Heart J 2003 24(17):1601-1610.

22. Hagstromer M, Oja P, Sjostrom M: The International Physical Activity Questionnaire (IPAQ): a study of concurrent and construct validity. Public Health Nutr 2006, 9(6):755-762.

23. Khan LK, Sobal J, Martorell R: Acculturation, socioeconomic status, and obesity in Mexican Americans, Cuban Americans, and Puerto Ricans. Int J Obes Relat Metab Disord 1997, 21(2):91-96.

24. Popkin BM, Udry JR: Adolescent obesity increases significantly in second and third generation U.S. immigrants: the National Longitudinal Study of Adolescent Health. J Nutr 1998, 128(4):701-706.

25. Arcia E, Skinner M, Bailey D, Correa V: Models of acculturation and health behaviors among Latino immigrants to the US. Soc Sci Med 2001, 53(1):41-53.

26. Alba $R$, Nee V: Rethinking assimilation theory for a new era of immigration. Int Migr Rev 1997, 31(4):826-874.

27. Leclere FB, Jensen L, Biddlecom AE: Health care utilization, family context, and adaptation among immigrants to the United States. $J$ Health SoC Behav 1994, 35(4):370-384

28. Shatenstein B, Nadon S, Godin C, Ferland G: Development and validation of a food frequency questionnaire. Can J Diet Pract Res 2005, 66(2):67-75.

29. Alkerwi A, Donneau AF, Sauvageot N, Lair ML, Albert A, Guillaume M: Dietary, behavioural and socio-economic determinants of the metabolic syndrome among adults in Luxembourg: findings from the ORISCAV-LUX study. Public Health Nutr 2011, 1-11. Epub 2011/09/15.

30. International Organization for Migration (IOM): Migration Facts \& Figures. 2009. http://www.iom.int/jahia/jsp/index.jsp.

31. Crespo CJ, Smit E, Carter-Pokras O, Andersen R: Acculturation and leisure-time physical inactivity in Mexican American adults: results from NHANES III, 1988-1994. Am J Public Health 2001, 91(8):1254-1257.

32. Vega WA, Amaro H: Latino outlook: good health, uncertain prognosis. Annu Rev Public Health 1994, 15:39-67.

33. Abraido-Lanza AF, Chao MT, Florez KR: Do healthy behaviors decline with greater acculturation? Implications for the Latino mortality paradox. Soc Sci Med 2005, 61(6):1243-1255.

34. Hoenig JM, Heisey DM: The Abuse of Power: The Pervasive Fallacy of Power Calculations for Data Analysis. Am Stat 2001, 55(1):19-24.

35. Singh GK, Siahpush M: All-cause and cause-specific mortality of immigrants and native born in the United States. Am J Public Health 2001, 91(3):392-399

36. Perdigao C, Rocha E, Duarte JS, Santos A, Macedo A: Prevalence and distribution of the main cardiovascular risk factors in Portugal-the AMALIA study. Rev Port Cardiol 2011, 30(4):393-432.

37. Alegria M: The challenge of acculturation measures: what are we missing? A commentary on Thomson \& Hoffman-Goetz. Soc Sci Med 2009, 69(7):996-998

38. Hawks SR, Madanat HN, Merrill RM, Goudy MB, Miyagawa T: A cross-cultural analysis of 'motivation for eating' as a potential factor in the emergence of global obesity: Japan and the United States. Health Promot Int 2003, 18(2):153-162.

39. Takata Y, Maskarinec G, Franke A, Nagata C, Shimizu H: A comparison of dietary habits among women in Japan and Hawaii. Public Health Nutr 2004, 7(2):319-326

\section{doi:10.1186/1471-2458-12-864}

Cite this article as: Alkerwi et al:: Acculturation, immigration status and cardiovascular risk factors among Portuguese immigrants to Luxembourg: findings from ORISCAV-LUX study. BMC Public Health 2012 $12: 864$ 